\title{
Sports competition related anxiety: Is it modifiable among athletes in urban schools in Sri Lanka?
}

\author{
Sumudu Rajasinghe a, ${ }^{\text {, }}$, Carukshi Arambepola ${ }^{\text {b }}$ \\ a Postgraduate Institute of Medicine, University of Colombo, Sri Lanka \\ b Department of Community Medicine, Faculty of Medicine, University of Colombo, Kynsey Road, Colombo 8, Sri Lanka \\ *Corresponding author Ph. No: 0094773862136; Email: sumuviraj@gmail.com \\ DOI: https://doi.org/10.54392/ajir2145 \\ Received: 12-07-2021; Revised: 05-11-2021; Accepted: 06-11-2021 Published: 08-11-2021
}

\begin{abstract}
Competition related anxiety is a major psychological issue among athletes and this study estimates the prevalence of competition related anxiety, its associated factors and coping strategies used, among school athletes in Sri Lanka. A cross-sectional study was conducted among 330 athletes. Two-stage simple random sampling was used. Competition related anxiety level was determined by Sport Competition Anxiety Test for adults (SCAT-A). Prevalence of 'high' level of sport competition related anxiety was $19.4 \%$ and it was significantly associated with individual sports, fear of failure, experience of past defeat, and poor support received from parents/friends. Listening to music, goal setting, positive self-talk and meditation were positive coping strategies used by athletes. The main negative coping strategy was being angry. High competition related anxiety prevalent in about $1 / 5^{\text {th }}$ of school athletes was influenced by several factors related to the sport event. Psychological support incorporated into routine physical training sessions is recommended.
\end{abstract}

Keywords: Urban school athletes, Competition related anxiety, Coping strategies

\section{Introduction}

Evidence suggests that participation in sports is associated with about $48 \%$ reduction in all-cause mortality compared with non-participation (Hansen et al., 2020). In addition, sports play a major role in health of an individual through its specific physical, psychological and social benefits, such as reducing body mass index, and improving physical fitness, stamina (Malm, Jakobsson \& Isaksson, 2019) social interactions and psychological well-being. However, it is also noted that the competitive nature of sports as well as expectations of high performance could put many athletes through an ample amount of stress and psychological issues. Many athletes struggle with such issues on a daily basis. Yet, since athletes are considered a physically fit and mentally resilient group of people (James et al., 2019) these issues are overlooked not only by the sport trainers but also by athletes themselves.

Common psychological issues identified related to sports include competition related anxiety, substance abuse and eating disorders (Schaal et al., 2011). 'Competition related anxiety in sports' is defined in different contexts but is uniquely measured in relation to impending competition. Martens et al (1990) defines it as 'a negative or unpleasant arousal that occurs prior to competition'. It is shown that such competition related anxiety can negatively affect the performance, leading to a large number of athletes discontinuing participation every year (Hassan et al., 2017). Further, it could affect their long-term health leading to depression, ulcers, burnout, inner conflict and sexual dysfunction (Rowland \& Van Lankveld, 2019; Shephard, 2017). In particular, school athletes are more at risk of developing competition related anxiety as they need to play the dual role of excelling at academic studies and sports, compared to the professional athletes who had left school (Mann et al., 2007). Therefore, the consequences of anxiety are expected to be far worse for school athletes, which has led for it to be a major contributory factor for school dropout among athletes (Hassan et al., 2017).

Over the recent years, awareness on competition related anxiety in the sports arena has increased to a level that quantification of such anxiety has become a necessity. Using the valid and reliable tools available worldwide 
studies have assessed the prevalence of competition related anxiety among athletes in different populations (Cox \& Cox, 2002; Küttel, Pedersen \& Larsen, 2021; Pluhar et al., 2019) from $8 \%$ to $48 \%$. However, only a few had been conducted among school athletes (Wilson, Raglin, Pritchard, 2002). Further, research has been conducted extensively among out-of-school athletes on the factors associated with competition related anxiety, such as gender, competitive experience, type of sport, competition venue, fear of failure, fear of negative social evaluation, influence from others and past defeat (Daryna, 2019; Rocha \& Osório 2018). However, these associations may differ in school athletes, considering the unique school environment that they interact with, peer and family influence, and their young age.

The field of sport psychology has advanced rapidly over the last decade, within which a variety of coping strategies such as self-talk, relaxation, engage in a hobby, meditation, praying, goal setting and social support have been introduced to athletes to counter-act competition related anxiety (Cox \& Cox, 2002). However, despite the wide availability, the actual use of these coping strategies by school athletes has not been assessed. Further, strategies used on their own, such as overeating, starvation, substance abuse and violent behaviour are also not well assessed.

In the Asian culture, sport participation has been an integral part of recreation and not done mainly for competition or commercial purpose. However, with the rapid economic and social development in the last few decades, sports in Asian countries have assumed a prominent place and along with it, sport participation especially in urban schools has substantially increased. This in turn has given rise to increased parental and school pressure to perform better, thus creating a highly competitive environment. Sri Lanka represents a country in the South Asian region with an interest on par with other countries in the region in nurturing skilled and healthy athletes at school level for the future. Despite achieving remarkable victories especially in cricket during the last two decades (Dharmadasa \& Perera, 2021)., studies show that only $40 \%$ of schools, $25 \%$ of sports clubs and $13 \%$ of universities were aware of and maintained training that addressed psychological aspects in athletes (Somaratne, 2014). This study was conducted to assess the prevalence of sport competition related anxiety, its associated factors and coping strategies used among school athletes in urban schools in Sri Lanka. Results will be applicable to similar countries in the region to call for necessary action to create an environment suitable for personal and professional development of young athletes in Asia.

\section{Methods}

A school-based cross-sectional study was conducted among school athletes in government secondary schools (classes included up to Grade 13) in one educational zone in the district of Colombo, Sri Lanka. The setting represented adolescents in schools located in the most urban area of the commercial capital of Sri Lanka, which had enough trainers and physical facilities provided by the government for all sports recommended by the ministry of education at school level. The sample consisted of athletes who were currently members of school teams in both indoor and outdoor sports which involve physical exertion and have represented the school at least in one event in their respective sport in the last six months. Athletes who were temporarily away from sports due to illnesses or injuries were excluded.

The minimal sample size was 342 calculated based on an expected proportion of 15\% (Cox \& Cox, 2002), precision of $5 \%, 95 \%$ confidence level and non-response of $10 \%$. A two-stage simple random sampling method was used to select the sample from Type IAB schools, which were larger in size and better equipped for sports than Type IC and Type 2 schools. In first stage, all 31Type IAB schools were stratified into three groups (13 - boys only, 13 girls only and 5 - mixed), from which two schools each were selected using computer generated random numbers. In the second stage, 57 athletes were selected randomly from each selected school. The sampling frame used for this purpose was an updated list compiled of the athletes scattered in different classes.

A self-administered questionnaire was prepared in local languages to obtain data on demographic and socioeconomic characteristics, description of the type and number of sports, coping strategies used and the support received. The level of sport competition related anxiety was assessed using the sport competition anxiety test for adults (SCAT-A) (Martens, Vealey \& Burton, 1990), which consists of 15 items that assesses both physical and mental aspects of anxiety on a three-point Likert scale ranging from 'Rarely' [1] to 'Often' [3]. The final score ranges from 10 to 30. SCAT-A has been widely used in research and demonstrates acceptable internal consistency (Cronbach alpha- 0.95 to 0.97 ) with test-retest reliability of 0.85 , and satisfactory content, concurrent and construct validity 
(Potgieter, 2009). The tool was culturally adapted for Sri Lanka after being translated using forward-backward translation method into the two main local languages by two independent language professionals. Its judgemental validity was assessed by an expert panel comprising a psychiatrist, psychologist, sport physician, sports instructor and a professional athlete. With less cultural variation shown, the original questions in the SCAT-A were retained, including the cut-off value of 24 originally developed to identify 'high' level of sport competition related anxiety. The translated questionnaire was pre-tested among 10 athletes randomly selected from a similar study setting. Reliability of the tool was assessed by re-administering it to a sub-sample of students in two weeks.

Ethics approval was obtained from the Ethics Review Committee of the Faculty of Medicine, University of Colombo, Sri Lanka. Prior to data collection, written informed consent was obtained from parents of the eligible athletes via a letter, and assent from athletes. Data collection was carried out in school on a convenient date. The data collectors were available for any clarifications. After the data collection, SCAT-A along with the marking scheme were distributed to teachers in order to facilitate counselling/psychiatry assistance, if required by the participants.

Data were analysed using the SPSS package, version 21. Findings were summarised in mean and standard deviation (SD) for numerical data, and proportions for categorical data. Mean composite scores were calculated based on the responses given in SCAT-A. The competition related anxiety level was categorized as 'normal' ( $<24$ in composite score) and 'high' ( $\geq 24$ in composite score). Factors associated with competition related anxiety were assessed using prevalence odds ratio (OR) and 95\% confidence interval using univariate analysis. To account for confounding effects, logistic regression analysis was performed with all the significant factors in univariate analysis included as the independent variables.

\section{Results}

A total of 330 school athletes participated in the study (response rate=96.5\%). Age of the participants ranged from 14 to 19 years with a mean age of $16.2(\mathrm{SD}=1.6)$ years. Majority (54.8\%) were male athletes. Mean scores obtained for competition related anxiety ranged from 14 to 29 , with a mean score of $19.9(\mathrm{SD}=3.6)$ and median (IQR) of 19.0 (4.0). Although the frequency distribution of SCAT-A mean scores was slightly right skewed (skewness value of 0.612 ), it could be approximated to a normal curve given the similarity observed in the measures of central tendency. The mean scores and confidence intervals for the items in SCAT-A are displayed in Figure 1.

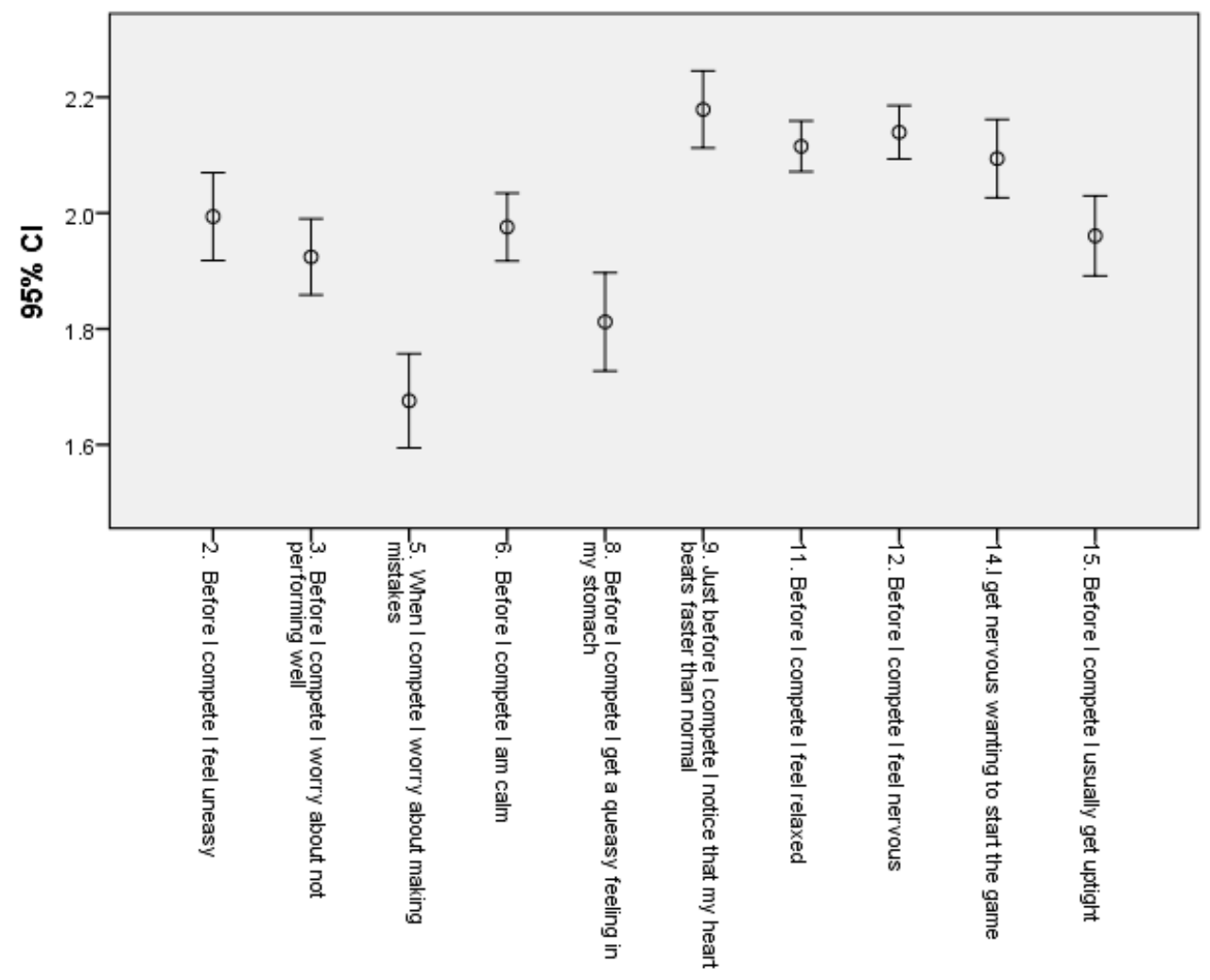

Figure 1. Mean scores and 95\% confidence intervals for the items in SCAT-A 
The prevalence of high level of sport competition related anxiety was 19.4\% (95\% CI: $15.3-24.1 \%$ ) $(n=64 / 330)$. Table 1 describes the socio-demographic factors associated with sport competition related anxiety.

Table 1. Socio-demographic factors associated with sport competition related anxiety levels among athletes

Socio demographic Total factors

\begin{tabular}{ccc}
\hline $\begin{array}{c}\text { Sports competition related } \\
\text { anxiety, No. }(\%)\end{array}$ & Prevalence OR & Significance \\
& $(95 \% \mathrm{CI})$ &
\end{tabular}

High ( $N=64) \quad$ Normal $(N=266)$

\begin{tabular}{llllll}
\hline Age & & & & \\
14-16 years & 186 & $38(20.4 \%)$ & $148(79.6 \%)$ & $1.2(0.7-2.0)$ & $\mathrm{X}^{2}=0.2$ \\
$17-19$ years & 144 & $26(18.1 \%)$ & $118(81.9 \%)$ & 1.0 & $\mathrm{df}=1, \mathrm{p}=0.7$ \\
\hline Sex & 149 & $33(21.5 \%)$ & $116(78.5 \%)$ & $1.4(0.8-2.5)$ & $\mathrm{X}^{2}=1.0$ \\
$\begin{array}{l}\text { Female } \\
\text { Male }\end{array}$ & 181 & $31(17.1 \%)$ & $150(82.9 \%)$ & 1.0 & $\mathrm{df}=1, \mathrm{p}=0.3$ \\
\hline Ethnicity & 6 & $2(33.3 \%)$ & $4(66.7 \%)$ & $2.0(0.4-10)$ & $\mathrm{X}^{2}=0.1$ \\
$\begin{array}{l}\text { Non-Sinhalese } \\
\text { Sinhalese }\end{array}$ & 324 & $62(18.8 \%)$ & $262(81.2 \%)$ & 1.0 & $\mathrm{df}=1, \mathrm{p}=0.7$ \\
\hline Religion & 314 & $61(19.1 \%)$ & $253(80.9 \%)$ & $1.1(0.3-3.8)$ & $\mathrm{X}^{2}=0.0$ \\
$\begin{array}{l}\text { Buddhists } \\
\text { Others } * *\end{array}$ & 16 & $3(18.8 \%)$ & $13(81.3 \%)$ & 1.0 & $\mathrm{df}=1, \mathrm{p}=1.0$ \\
\hline In an exam year & & & & & \\
Yes (Grade 10 \& 12) & 256 & $52(19.9 \%)$ & $204(80.1 \%)$ & $1.3(0.7-2.5)$ & $\mathrm{X}^{2}=0.4$ \\
No (Grade 11 \& 13) & 74 & $12(16.2 \%)$ & $62(83.8 \%)$ & 1.0 & $\mathrm{df}=1, \mathrm{p}=0.5$
\end{tabular}

None of these were significantly associated with high level of anxiety among the athletes $(p>0.05)$. Table 2 describes the sport event related factors that were significantly associated with a high level of competition related anxiety in the univariate and multivariate analyses.

Table 2. Factors associated with high level of sport competition anxiety in univariate and multivariate analyses

\begin{tabular}{lcccc} 
Characteristics & Total & $\begin{array}{c}\text { Sports competition related anxiety No. } \\
(\%)\end{array}$ & $\begin{array}{c}\text { Crude OR } \\
(95 \% ~ C I)\end{array}$ & $\begin{array}{c}\text { Adjusted OR } \\
(95 \% \mathrm{CI})\end{array}$ \\
\cline { 2 - 3 } & & &
\end{tabular}

\section{Type of sport}

$\begin{array}{llllll}\text { Individual } & 155 & 51(32.9 \%) & 104(67.1 \%) & 6.1(3.2-11.8) & 4.6(2.2-9.9) \\ \text { Other types }^{*} & 175 & 13(6.9 \%) & 162(93.1 \%) & 1.0 & 1.0\end{array}$

\section{No. of competitions During past one year}

\begin{tabular}{llllll} 
Less $(1-5)$ & 155 & $54(22.1 \%)$ & $190(77.9 \%)$ & $2.2(1.1-4.5)$ & $1.4(0.67-2.8)$ \\
More $(>5)$ & 175 & $10(11.6 \%)$ & $76(88.4 \%)$ & 1.0 & 1.0 \\
\hline $\begin{array}{llll}\text { Fear of failure } \\
\text { Yes }\end{array}$ & 256 & $64(24.6 \%)$ & $192(75.4 \%)$ & $1.3(1.2-1.4)$ & $2.6(1.2-5.8)$
\end{tabular}




\begin{tabular}{llllll}
\hline No & 74 & $0(0.0 \%)$ & $74(100.0 \%)$ & 1.0 & 1.0 \\
\hline Past defeat & & & & & \\
Yes & 248 & $62(25.0 \%)$ & $186(75.0 \%)$ & $13.3(3.2-55.8)$ & $3.4(1.2-10.1)$ \\
No & 82 & $2(2.4 \%)$ & $80(97.6 \%)$ & 1.0 & 1.0 \\
\hline
\end{tabular}

\section{Fear of negative social Evaluation}

$\begin{array}{llllll}\text { Yes } & 82 & 14(32.6 \%) & 29(67.4 \%) & 2.3(1.1-4.6) & 1.3(0.56-2.9) \\ \text { No } & 248 & 50(17.4 \%) & 237(82.6 \%) & 1.0 & 1.0\end{array}$

\section{Support given by Coach}

$\begin{array}{llllll}\text { Poor } & 173 & 8(53.3 \%) & 7(46.7 \%) & 5.6(1.8-15.2) & 2.0(0.71-5.4) \\ \text { Good } & 157 & 56(17.8 \%) & 259(82.2 \%) & 1.0 & 1.0\end{array}$

\section{Support given by Friends}

$\begin{array}{llllll}\text { Poor } & 196 & 5(71.4 \%) & 2(28.6 \%) & 11.2(2.1-58.8) & 9.4(2.2-39.9) \\ \text { Good } & 134 & 59(18.3 \%) & 264(81.7 \%) & 1.0 & 1.0\end{array}$

\section{Support given by Parents}

$\begin{array}{llllll}\text { Poor } & 31 & 23(74.2 \%) & 8(25.8 \%) & 18.1(7.6-43.1) & 7.1(2.3-21.7) \\ \text { Good } & 299 & 41(13.7 \%) & 258(86.3 \%) & 1.0 & 1.0\end{array}$

Of these factors, only six variables were retained in the regression model after adjusting for confounders, which were engagement in individual type of sport, having fear of failure, history of past defeats and poor support received from parents and friends. Figure 2 illustrates the positive coping strategies used among athletes.

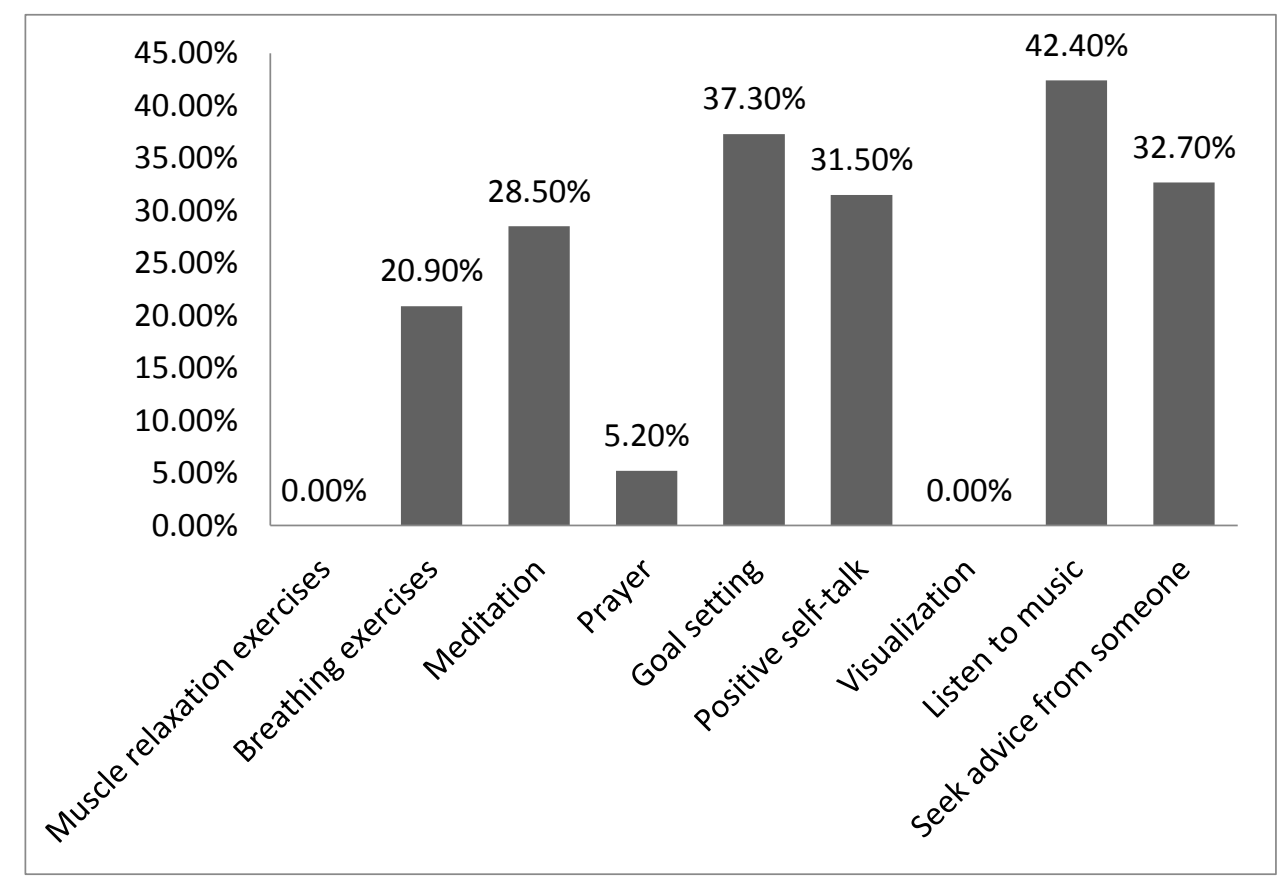

Figure 2. Commonly used positive coping strategies among athletes

As illustrated in Figure 2, a wide variety of positive coping strategies were commonly used by athletes. Of which the commonest was listening to music $(n=140,42.4 \%)$ followed by goal setting $(n=123,37.3 \%)$. The negative strategies used close to a competition were: being irritable with people around them (15.8\%); quarrelling with others 'most of the time' (11.5\%); and consuming energy drinks (39.1\%). The use of at least one coping strategy to overcome sport competition related anxiety was $84.2 \%(278 / 330)$. 


\section{Discussion}

Nurturing skilled as well as healthy athletes for the future should be addressed at a very early stage starting from school. Assessing the extent of the problem and factors underlying it will help in early identification of the most vulnerable ones for more focussed programmes to counteract competition related anxiety among school athletes. Our study shows that the prevalence of high level of sport competition related anxiety among athletes of urban schools in Sri Lanka was nearly $20 \%$. This prevalence was associated with several factors related to the sport they were engaged in and support received during sport, but not with any socio-demographic characteristic.

In this study, sport competition related anxiety was measured using the locally validated SCAT-A questionnaire and showed a mean score of $19.9(S D=3.6)$. Using the same tool, a similar mean score was reported in Asia in a sample of table tennis players in Taiwan (21.6, SD=3.57) (Chen et al., 2010) and a lower mean score in a study among futsal players in Iran (16.79, SD=2.1) (Mottaghi, Atarodi \& Rohani, 2013). This highlights a comparable burden of competition related anxiety in Asian countries. The slight discrepancy in scores could be due to the sample selected. Both Iran and Taiwan studies considered athletes from a single sport, whereas it was on any indoor or outdoor sport in the current study.

Our study reports a prevalence of high level of sport competition related anxiety among athletes of about $20 \%$. In comparison, a lower prevalence of $15.6 \%$ was reported in a study conducted in India among track and field athletes (Kar, 2013) and another study done in Unites States among University athletes (Proctor \& Boan-Lenzo, 2010). The major differences between these and our study was in relation to the application of social anxiety scale instead of SCAT-A, and athletes being of older age and out-of-school. School athletes are constantly burdened by their academic performance. In Sri Lanka, this could be the most crucial cause, as with the free education system at school, there is parental pressure for school children to devote more time to academic work, as academic excellence paves way for higher education and better employability. In contrast, excellence in sports is not recognised as much as an academic qualification for government employment in Sri Lanka. These findings are applicable to all other countries in South Asia, as poverty could worsen this situation, thus creating a highly competitive environment not suitable for the health of school athletes and their performance in both sports and education.

Previous studies have shown a significantly higher level of sport competition related anxiety amongthe females (Schaal et al., 2011; White \& Zellner, 1996). In contrast, the current study showed no such relationship, probably due to no known gender discrimination in relation to performance in Sri Lanka.

Regarding the sport related factors associated with high level of competition related anxiety, athletes who participated in individual type sports showed a four-fold risk. This finding is consistent with a study done in India (Kar, 2013) and could be explained by the shared responsibility existing within a team, and therefore competing as team members rather than as individuals is less likely to create pressure. In contrast, a study done in Brazil (Fernandes et al., 2013). revealed a low mean value for individual sports (1.7) compared to team events (1.96). However, the difference was not significant $(p>0.05)$.

Many studies have revealed that anxiety in sports is associated with both fear of failure (Kar, 2013; Sagar, Busch \& Jowett, 2010) and having past defeats (Jones \& Sheffield, 2007). These relationships were apparent in our study too. Flashbacks of past failures, especially if in the same environment of venue, team and weather conditions (Mottaghi, Atarodi \& Rohani 2013) seem to have a significant impact on the current performance. Therefore, psychological rehabilitation after a defeat or failure in a competition could be of immense help for athletes. This is extremely important in schools, since there is strong evidence of anxiety being lower among experienced athletes (Jones \& Sheffield, 2007) compared to almost all school athletes who have less exposure.

In sports, anxiety is particularly due to its competitive nature, which could be largely affected by the expectations of other people. Significant associations between sport competition anxiety and fear of negative social evaluation (Ridgers, Fazey \& Fairclough, 2007) as well as poor support from parents, friends, coaches and teachers (DeFreese \& Smith, 2013; Federici, \& Skaalvik, 2014; Mottaghi, Atarodi \& Rohani 2013) have been noted in previous studies. Our study revealed a significant $(p<.05)$ association independent of confounding effects with poor support from parents and friends. Parents play a major role in children's lives in Asia as they practise unique family centred and controlled child rearing practices. Hence, these children tend to be more dependent on their parents, family members and friends than the non-Asian children (Huang \& Gove 2015). These findings would be more accurate if 
studied using a qualitative design approach, as athletes may have unexplored types of influences which may not be apparent during a quantitative type of assessment.

Our study showed that the coping strategy most frequently used by athletes was listening to music (42\%). This was well over the proportions reported by others (Elliott, Polman \& Taylor, 2014; Karageorghis et al., 2006), and could be due to the less availability of other more sophisticated strategies specific for school athletes. Goal setting, positive self-talk, meditation, breathing exercises and cognitive-behavioural therapy have also been frequently used according to other studies (Chatzisarantis et al., 2003; Heiervang, Villabø \& Wergeland, 2018; Kross et al., 2014) in concurrence with ours. Along with these, negative coping strategies such as getting angry and quarrelling with others have been frequent among the study participants. It has shown that when provoked, athletes are more prone to aggressive behaviour than non-athletes (Maxwell, Moores \& Chow, 2007) thus discouraging such strategies is an important preventive measure of violence in sports. Energy drink consumption is the most apparent coping strategy that varies between male (64\%) and female (9\%) athletes. Such long-term consumption of energy drinks can contribute to obesity, increased blood pressure and blood glucose level, calcium deficiency, dental problems and depression in adult life (Wilson, Raglin \& Pritchard, 2002), thus a need for preventing it being used as a strategy.

Our study had several strengths. Selection bias was minimised by ensuring a representative sample of adequate size selected using a probability sampling method. Measurement errors were minimized by having a validated questionnaire that was culturally appropriate, simple and relatively short with minimal sensitive questions. Though judgemental validity of SCAT-A was well-confirmed, instrument bias should be duly acknowledged when interpreting results in this study. The study had a few limitations. Even though several factors seemed to be associated with anxiety, their temporal relationship cannot be established due to the cross-sectional nature of the study design. Further, the use of a self-administered questionnaire could have led to students giving exaggerated and socially desirable answers, and recall bias on situations around past competitions. Also, for some associations, the non-significant results obtained could have been due to lack of statistical power owing to small numbers in some categories.

\section{Conclusions}

Around $19 \%$ of school athletes in the most urban area in Sri Lanka showed a high level of sport competition related anxiety. Factors associated with high level of sport competition related anxiety were; engagement in individual type sport, having fear of failure and experience of past defeats, and poor support received from parents and friends. None were associated with their socio-demographic characteristics. Of the wide variety of coping strategies used by athletes, some were negative highlighting their vulnerability to health consequences. It is recommended that more emphasis be given to psychological aspects during sport training sessions, especially for those vulnerable to high level of competition related anxiety.

\section{References}

Chatzisarantis, N. L., Hagger, M. S., Biddle, S. J., Smith, B., \& Wang, J. C., (2003), A meta-analysis of perceived locus of causality in exercise, sport, and physical education contexts, Journal of sport and exercise psychology, 25(3), 284-306. https://doi.org/10.1123/jsep.25.3.284

Chen, I., Chang, C., Hung, C. L., Chen, L. C., \& Hung, T. M., (2010), Investigation of underlying psychological factors in elite table tennis players, International Journal of Table Tennis Sciences, 6, 48-50.

Cox, R. H., \& Cox, R. H., (2002), Sport psychology: Concepts and applications, McGraw-Hill, New York.

Daryna, I., Olha, B., Svitlana, F., Sergii, T., Iryna, K., Victoriia, M., \& Ion, M., (2019), Gender differences in competitive anxiety and coping strategies within junior handball national team, Electronic National University of Ukraine on Phisical Education and Sports Institutional Repository. http://reposit.unisport.edu.ua/handle/787878787/1826 
DeFreese, J. D., \& Smith, A. L., (2013), Teammate social support, burnout, and self-determined motivation in collegiate athletes, Psychology of Sport and Exercise, 14(2), 258-265. https://doi.org/10.1016/j.psychsport.2012.10.009

Dharmadasa, H. R., \& Perera, H. P. N., (2021), Facility Gaps for Players at International Cricket Stadiums in Sri Lanka vs. Australia, International Journal of Human Movement and Sports Sciences, 9(3), 590 - 594. https://doi.org/10.13189/saj.2021.090327

Elliott, D., Polman, R., \& Taylor, J., (2014), The effects of relaxing music for anxiety control on competitive sport anxiety, European journal of sport science, 14(sup1), S296-S301. https://doi.org/10.1080/17461391.2012.693952

Federici, R. A., \& Skaalvik, E. M., (2014), Students' Perceptions of Emotional and Instrumental Teacher Support: Relations with Motivational and Emotional Responses, International Education Studies, 7(1), 21-36. http://dx.doi.org/10.5539/ies.v7n1p21

Fernandes M.G., Nunes, S. A. N., Vasconcelos-Raposo, J., \& Fernandes, H. M., (2013), Factors influencing competitive anxiety in Brazilian athletes, Revista Brasileira de Cineantropometria \& Desempenho Humano, 15(6), 705 714. http://dx.doi.org/10.5007/1980-0037.2013v15n6p705

Hansen, B. H., Dalene, K. E., Ekelund, U., Wang Fagerland, M., Kolle, E., Steene-Johannessen, J., ... \& Alfred Anderssen, S., (2020), Step by step: Association of device-measured daily steps with all-cause mortalityA prospective cohort Study, Scandinavian Journal of Medicine \& Science in Sports, 30(9), 1705-1711. https://doi.org/10.1111/sms.13726

Hassan, A. R., Lam, M. H. S., Ku, S., Li, W. H. C., Lee, K. Y., Ho, E., ... \& Wong, A. S. W., (2017), The reasons of dropout of sport in Hong Kong school athletes, Health psychology research, 5(1). https://doi.org/10.4081/hpr.2017.6766

Heiervang, E. R., Villabø, M. A., \& Wergeland, G. J., (2018), Cognitive behavior therapy for child and adolescent anxiety disorders: an update on recent evidence, Current opinion in psychiatry, 31(6), 484-489. https://doi.org/10.1097/YCO.0000000000000457

Huang, G. H., \& Gove, M., (2015), Asian parenting styles and academic achievement: Views from eastern and western perspectives, Education, 135(3), 389-397.

James, M., Christian, D., Scott, S., Todd, C., Stratton, G., Demmler, J., \& Brophy, S., (2019), What works best when implementing a physical activity intervention for teenagers? Reflections from the ACTIVE Project: a qualitative study, BMJ open, 9(5), e025618. http://dx.doi.org/10.1136/bmjopen-2018-025618

Jones MV, \& Sheffield, D., (2007), The impact of game outcome on the well-being of athletes. International Journal of Sport and Exercise Psychology, 5(1), 54-65. https://doi.org/10.1080/1612197X.2008.9671812

Kar, S., (2013), Measurement of competition level anxiety of college level athletes by using SCAT, International Journal of Engineering Science and Innovative Technology, 2(3), 367-375.

Karageorghis, C. I., Priest, D. L., Terry, P. C., Chatzisarantis, N. L., \& Lane, A. M., (2006), Redesign and initial validation of an instrument to assess the motivational qualities of music in exercise: The Brunel Music Rating Inventory-2, Journal of sports sciences, 24(8), 899-909. https://doi.org/10.1080/02640410500298107

Kross, E., Bruehlman-Senecal, E., Park, J., Burson, A., Dougherty, A., Shablack, H.,\& Ayduk, O., (2014), Self-talk as a regulatory mechanism: how you do it matters, Journal of personality and social psychology, 106(2), 304. https://doi.org/10.1037/a0035173

Küttel, A., Pedersen, A. K., \& Larsen, C. H., (2021), To Flourish or Languish, that is the question: exploring the mental health profiles of Danish elite athletes, Psychology of Sport and Exercise, 52, 101837. https://doi.org/10.1016/j.psychsport.2020.101837

Malm, C., Jakobsson, J., \& Isaksson, A., (2019), Physical activity and sports-real health benefits: a review with insight into the public health of Sweden, Sports, 7(5), 127. https://doi.org/10.3390/sports7050127 
Mann, B. J., Grana, W. A., Indelicato, P. A., O'Neill, D. F., \& George, S. Z., (2007), A survey of sports medicine physicians regarding psychological issues in patient-athletes, The American journal of sports medicine, 35(12), 2140-2147. https://doi.org/10.1177/0363546507304140

Martens, R., Vealey, R. S., \& Burton, D., (1990), Competitive anxiety in sport, Human Kinetics, Champaign, IL.

Maxwell, J. P., Moores, E., \& Chow, C. C. F., (2007), Anger rumination and self-reported aggression amongst British and Hong Kong Chinese athletes: A cross cultural comparison, International Journal of Sport and Exercise Psychology, 5(1), 9-27. https://doi.org/10.1080/1612197X.2008.9671810

Mottaghi, M., Atarodi, A., \& Rohani, Z., (2013), The relationship between coaches' and athletes' competitive anxiety, and their performance, Iranian journal of psychiatry and behavioral sciences, 7(2), 68-76.

Pluhar, E., McCracken, C., Griffith, K. L., Christino, M. A., Sugimoto, D., \& Meehan III, W. P., (2019), Team sport athletes may be less likely to suffer anxiety or depression than individual sport athletes, Journal of sports science and medicine, 18(3), 490-496.

Potgieter, J. R., (2009), Norms for the Sport Competition Anxiety Test (SCAT), South African Journal for Research in Sport, Physical Education and Recreation, 31(1), 69-79. https://doi.org/10.4314/sajrs.v31i1.43793

Proctor, S. L., \& Boan-Lenzo, C., (2010), Prevalence of depressive symptoms in male intercollegiate student-athletes and nonathletes, Journal of Clinical Sport Psychology, 4(3), 204-220. https://doi.org/10.1123/jcsp.4.3.204

Ridgers, N. D., Fazey, D. M., \& Fairclough, S. J., (2007), Perceptions of athletic competence and fear of negative evaluation during physical education, British Journal of Educational Psychology, 77(2), 339-349. https://doi.org/10.1348/026151006X128909

Rocha, V. V. S., \& Osório, F. D. L., (2018), Associations between competitive anxiety, athlete characteristics and sport context: evidence from a systematic review and meta-analysis, Archives of Clinical Psychiatry (São Paulo), 45, 67-74. https://doi.org/10.1590/0101-60830000000160

Rowland, D. L., \& Van Lankveld, J. J., (2019), Anxiety and performance in sex, sport, and stage: identifying common ground, Frontiers in psychology, 10, 1615. https://doi.org/10.3389/fpsyg.2019.01615

Sagar, S. S., Busch, B. K., \& Jowett, S., (2010), Success and failure, fear of failure, and coping responses of adolescent academy football players, Journal of Applied Sport Psychology, 22(2), 213-230. https://doi.org/10.1080/10413201003664962

Schaal, K., Tafflet, M., Nassif, H., Thibault, V., Pichard, C., Alcotte, M., \& Toussaint, J. F., (2011), Psychological balance in high level athletes: gender-based differences and sport-specific patterns, PloS one, 6(5), e19007. https://doi.org/10.1371/journal.pone.0019007

Seifert, S. M., Schaechter, J. L., Hershorin, E. R., \& Lipshultz, S. E., (2011), Health effects of energy drinks on children, adolescents, and young adults. Pediatrics, 127(3), 511-528. https://doi.org/10.1542/peds.2009$\underline{3592}$

Shephard, R. J., (2017), Peptic ulcer and exercise, Sports Medicine, 47(1), 33-40. https://doi.org/10.1007/s40279016-0563-4

Somaratne GTUV, Nugaliyadda, N. T., Sarangika, N. G., Amarasinghe, M. C., Kahandawarachchi, C., \& Thelijjagoda, S., (2014), Enhancing the Selection Criteria and Achievement Level in Sri Lankan Sports.

White, S. A., \& Zellner, S. R., (1996), The relationship between goal orientation, beliefs about the causes of sport success, and trait anxiety among high school, intercollegiate, and recreational sport participants, The Sport Psychologist, 10(1), 58-72. https://doi.org/10.1123/tsp.10.1.58

Wilson, G. S., Raglin, J. S., \& Pritchard, M. E., (2002), Optimism, pessimism, and precompetition anxiety in college athletes, Personality and individual differences, 32(5), 893-902. https://doi.org/10.1016/S0191$\underline{8869(01) 00094-0}$ 
Does this article screened for similarity: Yes

Funding: No funding was received for conducting this study

Conflict of Interest: The authors have no conflicts of interest to declare that they are relevant to the content of this article.

\section{About The License}

(c) The author(s) 2021. The text of this article is open access and licensed under a Creative Commons Attribution 4.0 International License

\section{Cite this Article}

Sumudu Rajasinghe \& Carukshi Arambepola, Sports competition related anxiety: Is it modifiable among athletes in urban schools in Sri Lanka?, Asian Journal of Interdisciplinary Research, 4(4) (2021) 37-46. https://doi.org/10.54392/ajir2145 